
\title{
R Reserach S Suare \\ Involvement of Bradykinin and Folate receptor in calming the SARS-COV2 cytokine storm: Lessons learnt from lung cancer
}

\section{Pruthvi Gowda}

National Brain Research Centre

Ellora Sen ( $\nabla$ ellora@nbrc.ac.in )

National Brain Research Centre https://orcid.org/0000-0001-6842-7850

\section{Research Article}

Keywords: COVID-19, ACE2, BDKRB1, Nitric Oxide, Folate, Inflammation

Posted Date: April 22nd, 2020

DOI: https://doi.org/10.21203/rs.3.rs-23656/v1

License: (c) (1) This work is licensed under a Creative Commons Attribution 4.0 International License.

Read Full License 


\section{Abstract}

Background: Severe acute respiratory syndrome coronavirus (SARS-CoV2) is a highly pathogenic respiratory virus that causes morbidity and mortality in humans. The lungs are the major pathological target of SARS-CoV infection. The pathological derangements, aberrant signalling and dysregulated inflammation characteristics of lung cancer have marked similarities with the clinical manifestation of SARS-COV2 infection. As heightened inflammatory response is a key feature of both SARS-CoV infection and lung cancer and given the intriguing commonalities between the two, we analysed the RNA sequence dataset from lung cancer patients to get a better understanding of the critical regulators of inflammation in SAR-COV2.

Methods: The Cancer Genome Atlas (TCGA) data sets of lung cancer were analyzed for correlations between ACE2, Bradykinin, and other genes associated with inflammatory responses.

Results: TCGA dataset analysis indicated an inverse correlation between ACE2 and Bradykinin Receptor 1 (BDKRB1), IL-6 and IFNg in lung adenocarcinoma. A positive correlation between EGF, FOLR1, MAOA, NOSTRIN, MARC2, PHKD1, and ACE2 was noted

Summary: Our analysis has identified a common (i) ACE2- BDKRB1-inflammatory network and (ii) FOLR1Nitric oxide cross-talk in lung cancer and SARS-CoV2. Better understanding of the convergences between critical players in these networks would enable efficient repurposing of approved lung cancer therapeutics for COVID-19 infection.

\section{Background}

Identification of SARS-CoV in the lung tissue of all patients who died with probable severe acute respiratory syndrome (SARS) but not from non-SARS control, support the primary involvement of lungs in Coronaviruses (CoV) associated deaths [1]. Cytokine storm triggered by SARS-CoV induces strong proinflammatory response in the lungs which subsequently leads to pulmonary fibrosis [2]. Coronaviruses bind to their target cells through angiotensin- converting enzyme 2 (ACE2) [3], and infection is characterised by acute respiratory distress syndrome (ARDS). Loss of pulmonary ACE2 function has been associated with acute lung injury [4] and SARS-CoV infection [5].

The involvement of Bradykinin pathway in the response to ACE inhibition is well documented. Accumulation of Bradykinin- a 9 aa peptide generated under patho-physiologic conditions such as inflammation, shock, and allergy, contributes to the beneficial effects of ACE inhibitors [6]. Bradykinin mediates its effect through bradykinin receptors 1 and 2 (BDKRB1 and BDKRB2). While BDKRB2 is constitutively expressed in the endothelium, BDKRB1 levels are elevated in response to chronic inflammation [7, 8]. Reduction of Bradykinin degradation has been linked to ACE inhibitor-related angioedema [9]. 
Bradykinin and its receptors are involved in chronic inflammatory response in asthmatic airways [10]. SARS-CoV mediated increase in pro-inflammatory cytokine levels has been suggested to cause immunomediated damage to the lungs and other organs [11]. Reduction in pulmonary ACE2 activates BDKRB1 signalling, release of pro-inflammatory chemokines, neutrophil recruitment and exaggerated lung inflammation [12]. Besides, lung cancer cells use bradykinin as an autocrine factor to stimulate their growth [13], and the potential of Bradykinin antagonist in the treatment of lung cancer is recognized [14]. Bradykinin antagonist dimer is known to inhibit the growth of human lung cancer cell lines [15].

Given the commonalities between autosomal dominant polycystic kidney disease (ADPKD) and renal cell cancer [16], it has been suggested that comparison of these two diseases might indicate ways in which therapies developed for one disease might be applied to the other. Severely affected lungs characterised by pulmonary fibrosis is a major complication that accompanies SARS-CoV infection. With risk of lung cancer being higher in idiopathic pulmonary fibrosis [17], fibrotic changes in the lungs are common to both CoV infection and progression to lung cancer. Also, conformational fingerprinting of human ACE demonstrated significantly altered ACE expression and activity in tumor lung tissues [18].

Interestingly, the use of ACE inhibitors is associated with an increased risk of lung cancer [19]. Considering the common involvement of ACE2 in both lung cancer and SARS-CoV2 infection, we analysed the patient lung cancer TGCA dataset to find interaction between ACE2 and genes involved in the disease progression. We surmised that viewing SARS-CoV2 through the lens of lung cancer would deepen our understanding of the host responses in CoV infection through insights gained from lung cancer.

\section{Materials And Methods}

\section{Analysis of Lung Cancer data}

For studying the genes co-expressed with ACE2 in lung cancer, transcriptome sequencing (RNA-seq) data from TCGA Lung adenocarcinoma data set was downloaded from cBioPortal [20]. Spearman's rank correlation coefficient for RNA expression values of BDKRB1, IL6, IFNG, MAOA, NOSTRIN, FOLR1, MARC2, PHKD1, EGF and ACE2 in lung cancer was calculated using GraphPad Prism. Heatmap was plotted using Heatmapper [21]. The effect of positive regulators of ACE2 on BDKRB1-IL6-IFNg network was validated using Spearman's rank correlation analysis.

\section{Statistical analysis}

All correlation tests were performed using Spearman's rank correlation analysis unless otherwise stated. All p-values less than 0.05 were taken as significant.

\section{Results}




\section{Negative correlation between BDKRB1, IL6, IFNY and ACE2 in lung cancer}

On investigating the association between ACE2 and BDKRB1 in lung cancer patients, a negative correlation between the two was observed (Figure 1a). A negative correlation between pro-inflammatory IL-6, immune-modulatory cytokine Interferon gamma (IFNY) and ACE2 was also noted (Figure 1b). However, no significant association between ACE2 and other cytokines such as IL-1b, TNFa and CXCL8 was observed (Figure 1b).

\section{Genes with positive correlation with ACE2 in lung cancers}

A positive correlation was observed between ACE2 and Nitric Oxide Synthase Trafficking (NOSTRIN). Other genes such as EGF (Epidermal growth factor), FOLR1 (folate receptor a), MAOA (Monoamine oxidase), MARC2 (Mitochondrial amidoxime reducing component 2) and PKD1 (Polycystic kidney disease 1) were also found to be positively co-related with ACE2 (Figure 2a). The genes that were positively correlated with ACE2, was found to be negatively co-related with BDKRB1-IL6-IFNg network (Figure 3a).

\section{Discussion}

The most frequent co-morbidities reported with CoVID-19 patients on treatment with ACE inhibitors [22], suggests that ACE inhibition might worsen the consequences of infection. As the host response plays a determinant role in the pathogenesis of infectious diseases, strategies for treatment need to consider both the nature of host response as well as the microbial factors [23, 24]. We therefore questioned whether the effect of ACE inhibition on outcome of SARS-CoV infection is a consequence of its ability to modulate host response to infection rather than target the infection itself. As we reviewed the signalling pathways associated with aberrant inflammation in SARS-CoV infection under the lenses of lung cancer, the existence of a common ACE2- BDKRB1-inflammation cross talk in both became evident.

\section{A common ACE2-BDKRB1 cross talk in lung cancer and SARS-CoV2 infection regulate release of nitric oxide}

Given the implication of ACE2-BDKRB1 axis in the pathogenesis of acute lung inflammation [12], BDKRB1 has emerged as an important pharmacological target for treatment of inflammatory lung disorders. Phase I trial with the dual BDKRB1/2 antagonist B9870 (breceptin) has been conducted in lung cancer patients [25]. The predominant function of NOSTRIN is to reduce nitric oxide (NO) levels by sequestering eNOS within intracellular vesicular structures and rendering it inactive [26]. As positive co-relation was noted between ACE2 and NOSTRIN, it is likely that diminished NOSTRIN levels under ACE inhibition could elevate NO levels. Activation of BDKRB1 leads to very high and prolonged release of NO [27], and ACE 
inhibitors increase availability of NO by preventing the degradation of Bradykinin [28]. Antagonizing bradykinin receptors or nitric oxide synthase abolishes the cardioprotective effect of ACE inhibitor [29]. BDKRB1 is a potent activator of inducible form of NOS (iNOS), and the BDKRB1-iNOS auto-induction and amplification loop enhances inflammation in diabetic retinopathy [30]. This could explain severe COVID19 infection with co-morbidities in patient with diabetes mellitus who are often treated with ACE inhibitors [31]. mARC-1/2 which showed a positive correlation with ACE2 is known to catalyze NADH-dependent nitrite reduction to NO [32]. It is possible that co-expression of MARC and NOSTRIN under conditions of ACE inhibition play a role in regulating NO levels. Also, monoamine oxidases (MAOA) which is positively correlated with ACE2 negatively regulate IFNg inducible nitric oxide synthase gene expression [33]. Also, the association between PKD1 and ACE2 is interesting as loss of PKD1 expression increases the malignant potential of lung cancer [34], and acute renal failure is an important negative prognostic indicator for survival with SARS [35].

\section{ACE2-BDKRB1 nexus regulates inflammatory millieu}

Bradykinin sensitizes EGF induced signalling via Src-dependent enhanced phosphorylation of EGFR [36]. $\mathrm{NO}$ also induces activation of EGFR and its downstream signalling pathway [37]. It is tempting to speculate that elevated Bradykinin and NO levels upon ACE inhibition might heighten EGFR activation. Overactive EGFR signaling leads to increased pulmonary fibrosis after SARS-CoV infection [38], indicating that inhibiting EGFR signaling may prevent an excessive fibrotic response to corona viruses [39]. EGFR enables sustained IL-6 dependent STAT3 activation to promote inflammation [40], and IL-6R antagonist Sarilumab (Kevzara) is set to enter for clinical trial in COVID-19. Besides, several EGFR inhibitors are among FDA approved drugs for lung cancer (Supplementary List). Bradykinin induces IL-6 secretion in human airway smooth muscles [41]. While IFN-y is capable of partly inhibiting SARS-CoV replication through down-regulation of ACE2 [42], it can also amplify pro- inflammatory cytokine mediated increase in BDKRB1 expression and abundance in endothelial cells [43].

\section{Folate and viral load}

Considering its positive co-relation with ACE2, inhibiting FOLR1 carries the risk of activating BDKRB1. However, as folic acid and its active metabolite 5-methyl tetrahydrofolate improves NO bioavailability [44], FOLR1 inhibition can reduce NO mediated inflammation. In patient with primary lung cancer, elevated exhaled NO production from alveolar macrophages and increase in iNOS activity has been noted [45]. Given its role in the pathogenesis of inflammation, NO inhibitors are considered in the management of inflammatory diseases [10]. NG-monomethyl-L-arginine (L-NMMA) a nitric oxide synthase inhibitor has been suggested [46], and is in clinical trial for lung cancer (ClinicalTrials.gov Identifier: NCT03236935). Importantly, FOLR1 is over-expressed in lung cancer and among the several FDA approved drugs for lung cancer, folate inhibitors such as Methotrexate (Trexall) and Pemetrexed disodium finds a place 
(Supplementary List). An ongoing phase II clinical trial is evaluating farletuzumab (a monoclonal antibody targeting FOLR1) in patients with lung adenocarcinoma [47].

Most interestingly, folic acid has a critical role in determining the outcome of lymphocytic choriomeningitis (LCM) infection, as a folic acid antagonist amethopterin enhanced survival of the host despite prolonged viraemia [48]. FOLR1 is a significant cofactor for cellular entry for Marburg and Ebola viruses [49]. Human cytomegalovirus (HCMV) infection stimulates activity of cellular dihydrofolate reductase (DHFR) and inhibition of DHFR activity by methotrexate prevented HCMV replication [50]. Pemetrexed disodium- a novel multitargeted antifolate is used in the treatment of lung cancer (Supplementary list). Recent review has highlighted the importance of folate in natural killer cell dysfunction and viral etiology in type 1 diabetes [51].

\section{Evaluation of anti-lung cancer agents for COVID-19}

Our findings suggest that ACE2-BDKRB1 associated molecular pathways regulate inflammatory milieu in the lungs under pathological conditions (Fig. 3b). Also, existing literature points to the requirement of folate for efficient viral replication. Pro-inflammatory cytokines are highly up-regulated in serum from SARS-CoV patients $[52,53]$. As the signalling pathways associated with inflammation show striking similarities between SARS- COV2 infection and lung cancers, repurposing of anti-lung cancer drugs for COVID-19 has considerable promise (Fig. 3c). The Damage-Response Framework (DRF) tool that integrates clinical findings with microbiology and immunology [24], highlights the indispensable role of host response in determining the outcome of microbial pathogenesis in response to anti-inflammatory agents. Most COVID-19 deaths involved older adults having had underlying chronic illnesses, with several on ACE inhibitors. Therefore, leveraging host response while targeting (i) ACE2-BDKRB1-inflammatory network and (ii) folate-nitric oxide for COVID- 19 treatment will determine therapeutic success.

\section{Folate, malaria and CoV: Where does the connection lie?}

Folate metabolism impairment is associated with malarial parasite infection [54]. The anti- malarial agent hydroxyl-chloroquine (HCQ) with immunomodulatory properties widely used for the treatment of rheumatoid arthritis and systemic lupus erythematosus, has been effective in inhibiting SARS-CoV-2 infection in vitro [55]. It has been suggested that HCQ attenuates COVID-19 progression by inhibiting the cytokine storm [56]. As Bradykinin induced release of prostaglandins is inhibited by chloroquine [57], it is possible that HCQ controls the inflammatory milieu in COVID-19 patients by attenuating Bradykinin induced inflammatory mediators. Also, HCQ inhibits NO production [58]. Though no direct association between HCQ and folate metabolism has been reported, it is also possible that effect of HCQ on COVID19 is a consequence of its action on FOLR1 dependent nitric oxide generation.

\section{Conclusion}


As SARS-CoV2 infections are characterised by an aberrant inflammatory response, a combinations of anti-viral and anti-inflammatory has been suggested for reducing viral infectivity and dysregulated host inflammatory response [59]. With the pandemic human pathogenic coronavirus disease 2019 (COVID-19) spreading unabated, the current challenges are to identify therapeutic strategies and efficiently evaluate their activity in clinical setting. This comparative analysis has highlighted that functional integration of diverse intracellular signalling networks in lung cancer can be extrapolated to explain the aberrant inflammatory response in COVID-19 infection. Our finding suggests that therapeutics with safety and tolerability profiles in lung cancers targeting BDKRB1 and FOLR1 could be repurposed for calming the cytokine storm in COVID-19 infection.

\section{Abbreviations}

ACE2: angiotensin-converting enzyme 2, EGFR: epidermal growth factor receptor, NO: Nitric oxide, NOSTRIN: Nitric Oxide Synthase Trafficking, TCGA: The Cancer Genome Atlas, IL-1 $\beta$ : Interleukin 1 beta, IL6: Interleukin 6, IFNG: Interferon Gamma, TNF a: Tumor necrosis factor, CXCL8: Chemokine (C-X-C motif) ligand, EGF: Epidermal growth factor, FOLR1: Folate receptor a, MAOA: Monoamine oxidase, MARC2: Mitochondrial amidoxime reducing component 2 and PKD1: Polycystic kidney disease 1

\section{Declarations}

\section{Ethics approval and consent to participate}

Not applicable

\section{Consent for publication}

Not applicable

\section{Availability of data and material}

The datasets used and/or analyzed during the current study are available from the corresponding author on reasonable request.

\section{Funding}

The work was supported by a research grant from the Department of Biotechnology to ES (DBT, Government of India, BT/MED/30/SP11016/2015).

\section{Competing interests}

The authors declare that they have no competing interests.

\section{Authors' contributions}


Pruthvi Gowda and Ellora Sen designed the study. Pruthvi Gowda performed data acquisition. Both authors wrote, read and approved the manuscript

\section{Acknowledgements}

All Lung Cancer and COVID-19 patients.

\section{References}

1. Huang CD, Tliba O, Panettieri RA, Jr., Amrani Y. Bradykinin induces interleukin-6 production in human airway smooth muscle cells: modulation by Th2 cytokines and dexamethasone. American journal of respiratory cell and molecular biology. 2003 Mar;28(3):330-8.

2. Wang $Y$, van Boxel-Dezaire AH, Cheon $H$, Yang J, Stark GR. STAT3 activation in response to IL- 6 is prolonged by the binding of IL- 6 receptor to EGF receptor. Proceedings of the National Academy of Sciences of the United States of America. Oct 15;110(42):16975-80.

3. Venkataraman T, Frieman MB. The role of epidermal growth factor receptor (EGFR) signaling in SARS coronavirus-induced pulmonary fibrosis. Antiviral research. Jul;143:142-50.

4. Venkataraman T, Coleman CM, Frieman MB. Overactive Epidermal Growth Factor Receptor Signaling Leads to Increased Fibrosis after Severe Acute Respiratory Syndrome Coronavirus Infection. Journal of virology. Jun 15;91(12).

5. Lee HC, An S, Lee H, Woo SH, Jin HO, Seo SK, et al. Activation of epidermal growth factor receptor and its downstream signaling pathway by nitric oxide in response to ionizing radiation. Mol Cancer Res. 2008 Jun;6(6):996-1002.

6. Hur EM, Park YS, Lee BD, Jang IH, Kim HS, Kim TD, et Sensitization of epidermal growth factorinduced signaling by bradykinin is mediated by c-Src. Implications for a role of lipid microdomains. The Journal of biological chemistry. 2004 Feb 13;279(7):5852-60.

7. Chu KH, Tsang WK, Tang CS, Lam MF, Lai FM, To KF, et al. Acute renal impairment in coronavirusassociated severe acute respiratory syndrome. Kidney international. 2005 Feb;67(2):698-705.

8. Ni Y, Wang L, Zhang J, Pang Z, Liu Q, Du J. PKD1 is downregulated in non-small cell lung cancer and mediates the feedback inhibition of mTORC1-S6K1 axis in response to phorbol ester. The international journal of biochemistry \& cell biology. Mar;60:34-42.

9. Vega A, Chacon P, Monteseirin J, El Bekay R, Alvarez M, Alba G, et al. A new role for monoamine oxidases in the modulation of macrophage-inducible nitric oxide synthase gene expression. Journal of leukocyte biology. 2004 Jun;75(6):1093-101.

10. Sparacino-Watkins CE, Tejero J, Sun B, Gauthier MC, Thomas J, Ragireddy V, et al. Nitrite reductase and nitric-oxide synthase activity of the mitochondrial molybdopterin enzymes mARC1 and mARC2. The Journal of biological chemistry. Apr 11;289(15):10345-58.

11. Fang L, Karakiulakis G, Roth M. Are patients with hypertension and diabetes mellitus at increased risk for COVID-19 infection? The Lancet. Mar 
12. Othman R, Vaucher E, Couture R. Bradykinin Type 1 Receptor - Inducible Nitric Oxide Synthase: A New Axis Implicated in Diabetic Frontiers in pharmacology.10:300.

13. Hartman JC. The role of bradykinin and nitric oxide in the cardioprotective action of ACE inhibitors. The Annals of thoracic surgery. 1995 Sep;60(3):789-92.

14. Ancion A, Tridetti J, Nguyen Trung ML, Oury C, Lancellotti P. A Review of the Role of Bradykinin and Nitric Oxide in the Cardioprotective Action of Angiotensin-Converting Enzyme Inhibitors: Focus on Perindopril. Cardiology and therapy. Dec;8(2):179-91.

15. Kuhr F, Lowry J, Zhang Y, Brovkovych V, Skidgel RA. Differential regulation of inducible and endothelial nitric oxide synthase by kinin B1 and B2 receptors. Neuropeptides. Apr;44(2):145-54.

16. Zimmermann K, Opitz N, Dedio J, Renne C, Muller-Esterl W, Oess S. NOSTRIN: a protein modulating nitric oxide release and subcellular distribution of endothelial nitric oxide synthase. Proceedings of the National Academy of Sciences of the United States of America. 2002 Dec 24;99(26):17167-72.

17. da Costa PL, Sirois P, Tannock IF, Chammas R. The role of kinin receptors in cancer and therapeutic opportunities. Cancer letters. Apr 1;345(1):27-38.

18. Pirofski LA, Casadevall A. The Damage-Response Framework as a Tool for the Physician- Scientist to Understand the Pathogenesis of Infectious Diseases. The Journal of infectious diseases. Aug 14;218(suppl_1):S7-S11.

19. Casadevall A, Pirofski LA. What Is a Host? Attributes of Individual Susceptibility. Infection and immunity. Feb;86(2).

20. Mazzulli T, Farcas GA, Poutanen SM, Willey BM, Low DE, Butany J, et al. Severe acute respiratory syndrome-associated coronavirus in lung tissue. Emerging infectious diseases. 2004 Jan;10(1):20-4.

21. Tisoncik JR, Korth MJ, Simmons CP, Farrar J, Martin TR, Katze Into the eye of the cytokine storm. Microbiol Mol Biol Rev. Mar;76(1):16-32.

22. Wu K, Li W, Peng G, Li F. Crystal structure of NL63 respiratory coronavirus receptor-binding domain complexed with its human receptor. Proceedings of the National Academy of Sciences of the United States of America. 2009 Nov 24;106(47):19970-4.

23. Imai Y, Kuba K, Rao S, Huan Y, Guo F, Guan B, et al. Angiotensin-converting enzyme 2 protects from severe acute lung failure. Nature. 2005 Jul 7;436(7047):112-6.

24. Kuba K, Imai Y, Rao S, Gao H, Guo F, Guan B, et A crucial role of angiotensin converting enzyme 2 (ACE2) in SARS coronavirus-induced lung injury. Nature medicine. 2005 Aug;11(8):875-9.

25. Tom B, Dendorfer A, de Vries R, Saxena PR, Jan Danser AH. Bradykinin potentiation by ACE inhibitors: a matter of metabolism. British journal of pharmacology. 2002 Sep;137(2):276-84.

26. Marceau F, Bachvarov Kinin receptors. Clinical reviews in allergy \& immunology. 1998 Winter;16(4):385-401.

27. Marceau F, Hess JF, Bachvarov DR. The B1 receptors for kinins. Pharmacological reviews. 1998 Sep;50(3):357-86. 
28. Anderson MW, deShazo RD. Studies of the mechanism of angiotensin-converting enzyme (ACE) inhibitor-associated angioedema: the effect of an ACE inhibitor on cutaneous responses to bradykinin, codeine, and histamine. The Journal of allergy and clinical immunology. 1990 May;85(5):856-8.

29. Sharma JN, Al-Omran A, Parvathy SS. Role of nitric oxide in inflammatory diseases. Inflammopharmacology. 2007 Dec;15(6):252-9.

30. He L, Ding Y, Zhang Q, Che $X, \mathrm{He} Y$, Shen $\mathrm{H}$, et al. Expression of elevated levels of pro- inflammatory cytokines in SARS-CoV-infected ACE2+ cells in SARS patients: relation to the acute lung injury and pathogenesis of SARS. The Journal of pathology. 2006 Nov;210(3):288-97.

31. Sodhi CP, Wohlford-Lenane C, Yamaguchi Y, Prindle T, Fulton WB, Wang S, et al. Attenuation of pulmonary ACE2 activity impairs inactivation of des-Arg(9) bradykinin/BKB1R axis and facilitates LPS-induced neutrophil infiltration. Am J Physiol Lung Cell Mol Physiol. Jan 1;314(1):L17-L31.

32. Bunn PA, , Dienhart DG, Chan D, Tagawa M, Jewett P. Effects of neuropeptides on human lung and breast cancer cells. Journal of the National Cancer Institute. 1992(13):145-51.

33. Stewart JM, Gera L, Chan DC, York EJ, Stewart LT, Simkeviciene V, et al. New lung cancer drugs from bradykinin antagonists. Chest. 2004 May;125(5 Suppl):148S.

34. Chan D, Gera L, Stewart J, Helfrich B, Verella-Garcia M, Johnson G, et al. Bradykinin antagonist dimer, CU201, inhibits the growth of human lung cancer cell lines by a "biased agonist" mechanism. Proceedings of the National Academy of Sciences of the United States of America. $2002 \mathrm{Apr}$ 2;99(7):4608-13.

35. Seeger-Nukpezah T, Geynisman DM, Nikonova AS, Benzing T, Golemis EA. The hallmarks of cancer: relevance to the pathogenesis of polycystic kidney disease. Nat Rev Nephrol. Sep;11(9):515-

36. Han S, Lee YJ, Park JS, Cho YJ, Yoon HI, Lee JH, et al. Prognosis of non-small-cell lung cancer in patients with idiopathic pulmonary fibrosis. Scientific reports. Aug 29;9(1):12561.

37. Danilov SM, Metzger R, Klieser E, Sotlar K, Trakht IN, Garcia JGN. Tissue ACE phenotyping in lung cancer. PloS 14(12):e0226553.

38. Hicks BM, Filion KB, Yin H, Sakr L, Udell JA, Azoulay L. Angiotensin converting enzyme inhibitors and risk of lung cancer: population based cohort study. BMJ (Clinical research ed. Oct 24;363:k4209.

39. Gao J, Aksoy BA, Dogrusoz U, Dresdner G, Gross B, Sumer SO, et al. Integrative analysis of complex cancer genomics and clinical profiles using the cBioPortal. Science signaling. Apr 2;6(269):pl1.

40. Babicki S, Arndt D, Marcu A, Liang Y, Grant JR, Maciejewski A, et al. Heatmapper: web- enabled heat mapping for all. Nucleic acids research. Jul 8;44(W1):W147-53.

41. Guan WJ, Ni ZY, Hu Y, Liang WH, Ou CQ, He JX, et al. Clinical Characteristics of Coronavirus Disease 2019 in China. The New England journal of medicine. Feb

42. de Lang A, Osterhaus AD, Haagmans BL. Interferon-gamma and interleukin-4 downregulate expression of the SARS coronavirus receptor ACE2 in Vero E6 cells. Virology. 2006 Sep 30;353(2):474- 
43. Koumbadinga GA, Desormeaux A, Adam A, Marceau F. Effect of interferon-gamma on inflammatory cytokine-induced bradykinin B1 receptor expression in human vascular cells. European journal of pharmacology. Nov 25;647(1-3):117-25.

44. Stanhewicz AE, Kenney WL. Role of folic acid in nitric oxide bioavailability and vascular endothelial function. Nutrition reviews. Jan;75(1):61-70.

45. Liu CY, Wang CH, Chen TC, Lin HC, Yu CT, Kuo HP. Increased level of exhaled nitric oxide and upregulation of inducible nitric oxide synthase in patients with primary lung cancer. British journal of cancer. 1998 Aug;78(4):534-41.

46. Pershing NL, Yang CFJ, Xu M, Counter CM. Treatment with the nitric oxide synthase inhibitor L-NAME provides a survival advantage in a mouse model of Kras mutation-positive, non-small cell lung cancer. Oncotarget. Jul 5;7(27):42385-92.

47. Thomas A, Maltzman J, Hassan R. Farletuzumab in lung cancer. Lung cancer (Amsterdam, Netherlands). Apr;80(1):15-8.

48. Haas VH, Stewart SE, Briggs Folic acid deficiency and the sparing of mice infected with the virus of lymphocytic choriomeningitis. Virology. 1957 Feb;3(1):15-21.

49. Chan SY, Empig CJ, Welte FJ, Speck RF, Schmaljohn A, Kreisberg JF, et al. Folate receptor- alpha is a cofactor for cellular entry by Marburg and Ebola Cell. $2001 \mathrm{Jul}$ 13;106(1):117-26.

50. Lembo D, Gribaudo G, Cavallo R, Riera L, Angeretti A, Hertel L, et Human cytomegalovirus stimulates cellular dihydrofolate reductase activity in quiescent cells. Intervirology. 1999;42(1):30-6.

51. Bayer AL, Fraker The Folate Cycle As a Cause of Natural Killer Cell Dysfunction and Viral Etiology in Type 1 Diabetes. Frontiers in endocrinology.8:315.

52. Huang KJ, Su IJ, Theron M, Wu YC, Lai SK, Liu CC, et al. An interferon-gamma-related cytokine storm in SARS patients. Journal of medical virology. 2005 Feb;75(2):185-94.

53. Wong CK, Lam CW, Wu AK, Ip WK, Lee NL, Chan IH, et al. Plasma inflammatory cytokines and chemokines in severe acute respiratory syndrome. Clinical and experimental immunology. 2004 Apr;136(1):95-103.

54. Chango A, Abdennebi-Najar L. Folate metabolism pathway and Plasmodium falciparum malaria infection in pregnancy. Nutrition reviews. Jan;69(1):34-40.

55. Liu J, Cao R, Xu M, Wang X, Zhang H, Hu H, et al. Hydroxychloroquine, a less toxic derivative of chloroquine, is effective in inhibiting SARS-CoV-2 infection in vitro. Cell 6:16.

56. Zhou D, Dai SM, Tong Q. COVID-19: a recommendation to examine the effect of hydroxychloroquine in preventing infection and progression. The Journal of antimicrobial chemotherapy. Mar

57. Damas J, Deby C. [Release of prostaglandins and their precursors by bradykinin]. Archives internationales de physiologie et de biochimie. 1976 Apr;84(2):293-304.

58. Perecko T, Kassab RB, Vasicek O, Pekarova M, Jancinova V, Lojek A. The effects of chloroquine and hydroxychloroquine on nitric oxide production in RAW 7 and bone marrow- derived macrophages. Folia biologica.60 Suppl 1:39-44. 
59. Stebbing J, Phelan A, Griffin I, Tucker C, Oechsle O, Smith D, et al. COVID-19: combining antiviral and anti-inflammatory treatments. Lancet Infect Dis. Feb

\section{Figures}

Figure 1

A

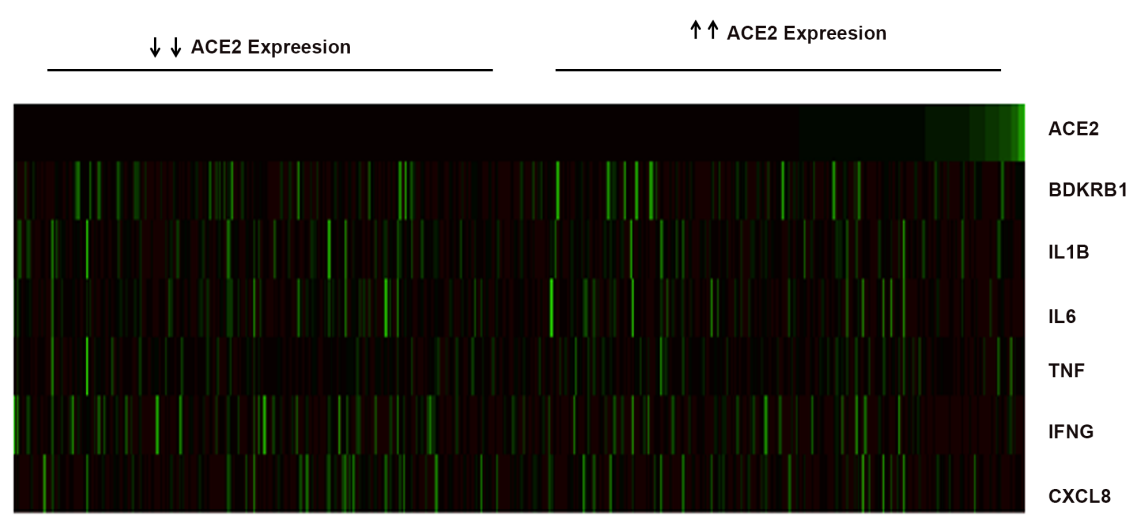

LUNG ADENOCARCINOMA (TGCA, PANCANCER ATLAS) $(n=503)$

B
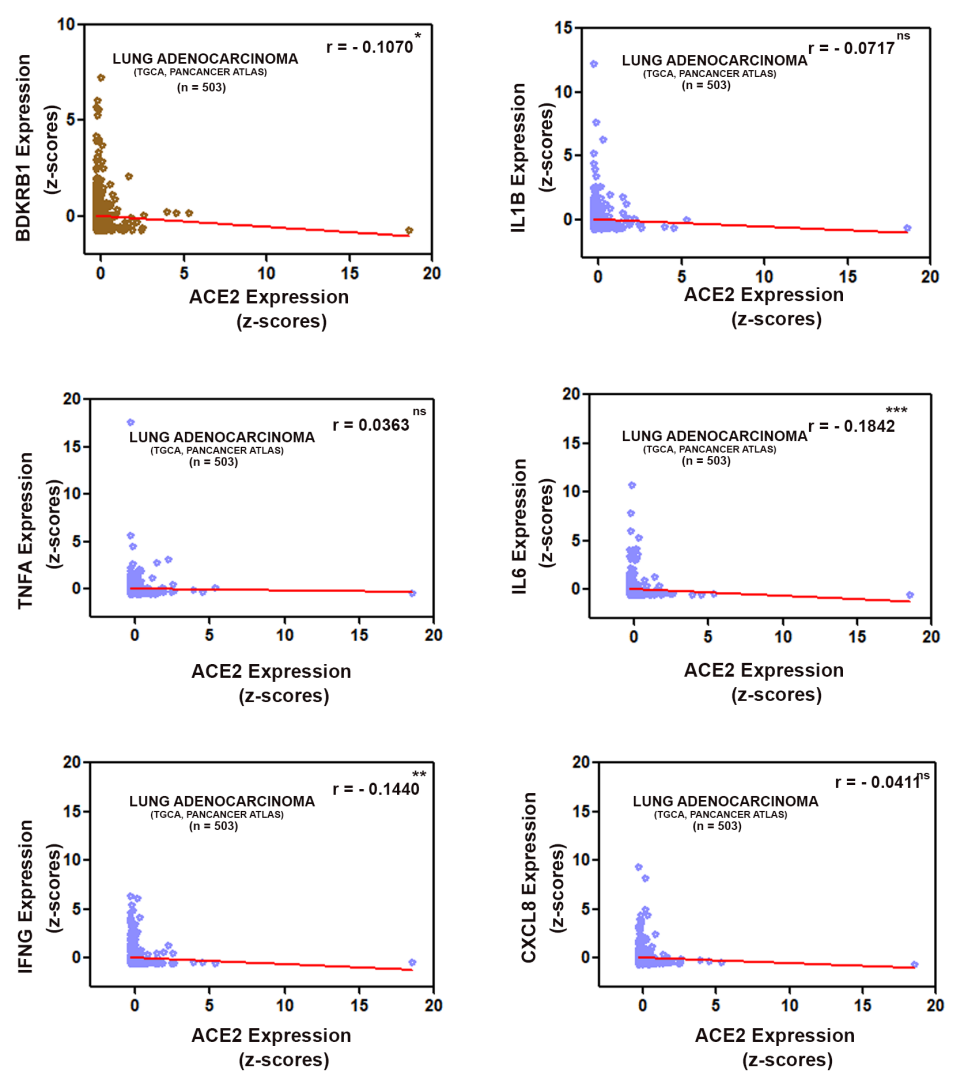

Figure 1 
ACE2 is negatively correlated with bradykinin receptor and cytokines. (A) Heatmap illustrating the expression levels of ACE2 and cytokine family proteins. A negative correlation of ACE2 with these genes suggests involvement of ACE2 in altering cytokine storm. (B) Individual correlation of ACE2 with these genes is shown. BDKRB1, IL6 and IFNG were found to be significantly correlated with ACE2 expression. *, $\mathrm{P}<0.05 ; * \star, \mathrm{P}<0.01 ; * \star *, \mathrm{P}<0.001, \mathrm{r}$ - Spearman's rank correlation coefficient.

Figure 2
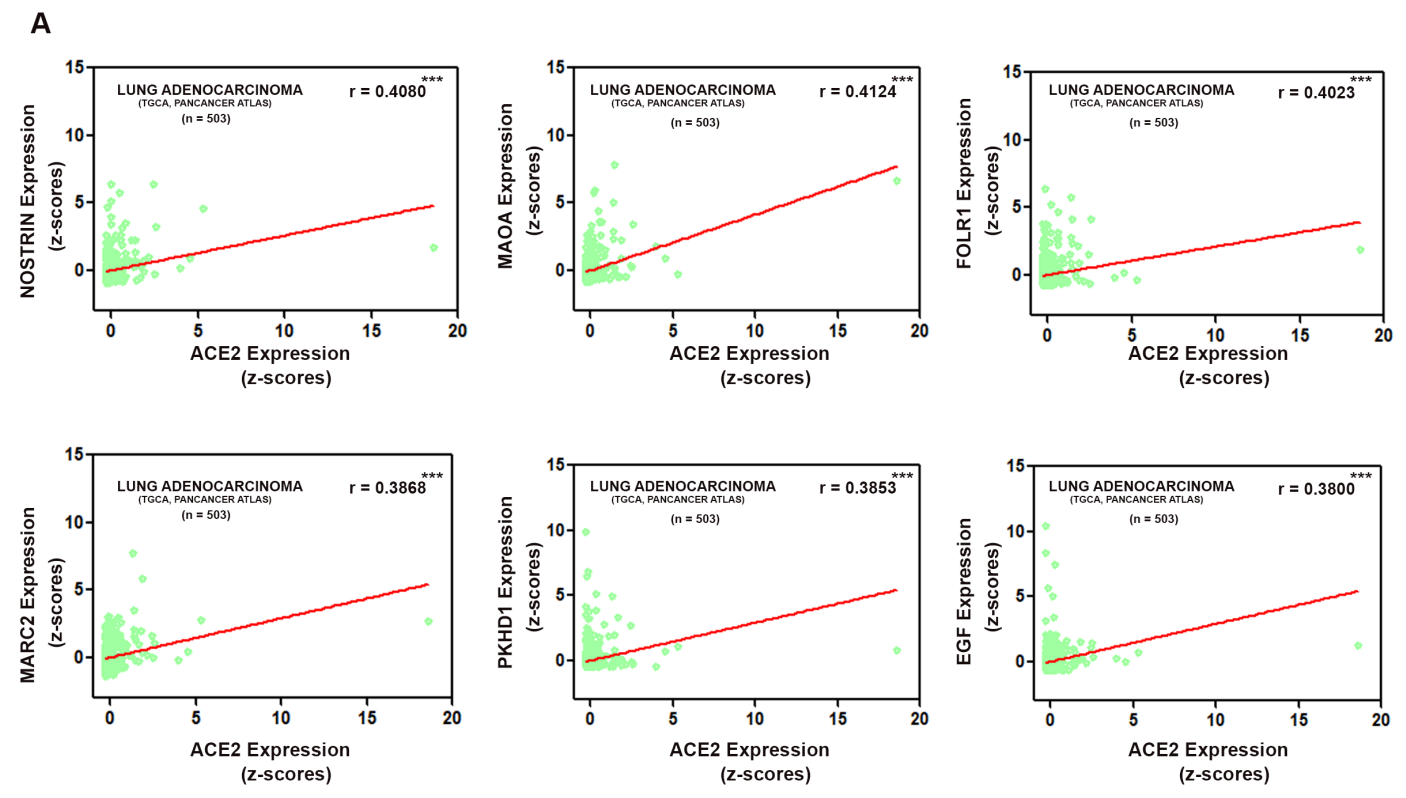

Figure 2 
Genes positively correlated with ACE2 in lung cancers. (A) Genes with positive correlations with ACE2 is shown. MAOA, NOSTRIN, FOLR1, MARC2, PHKD1, EGF were found to be significantly correlated with ACE2 expression. $*, \mathrm{P}<0.05 ; * \star, \mathrm{P}<0.01 ; * \star \star, \mathrm{P}<0.001, \mathrm{r}$ - Spearman's rank correlation coefficient.

Figure 3

A
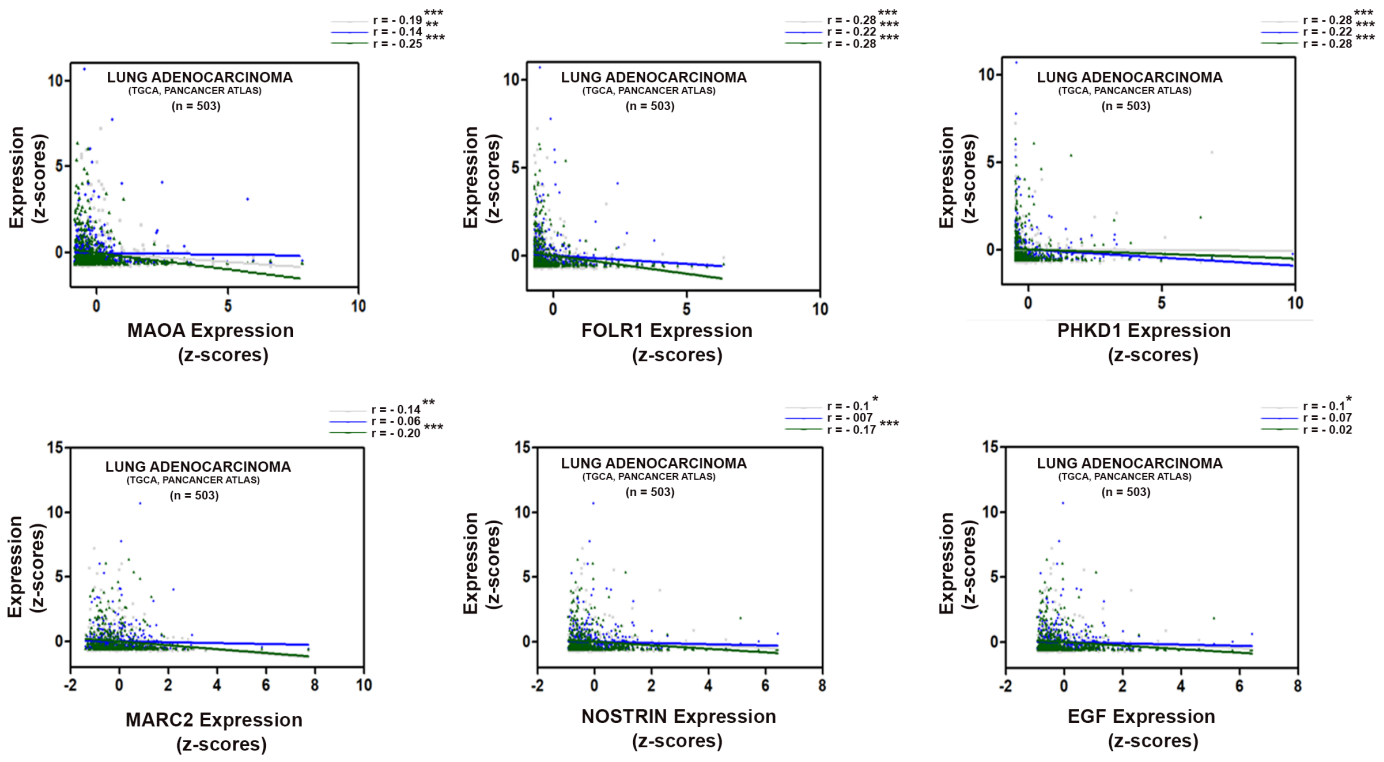

B

C

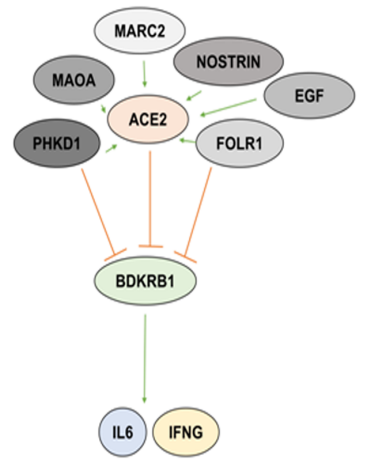

\begin{tabular}{|l|l|l|l|}
\hline Target & $\begin{array}{l}\text { Product type/ } \\
\text { Candidate } \\
\text { drugs }\end{array}$ & Description & Reference \\
\hline BDKRB1/2 & $\begin{array}{l}\text { B9870 } \\
\text { (breceptin) }\end{array}$ & $\begin{array}{l}\text { Lung Cancer } \\
\text { (Under Phase-I } \\
\text { Trials) }\end{array}$ & $\begin{array}{l}\text { da Costa PL et.al, } \\
\text { Cancer Lett. 2014 }\end{array}$ \\
\hline Nitric Oxide & L-NMMA & $\begin{array}{l}\text { Lung Cancer } \\
\text { (Under Clinical } \\
\text { Trials) }\end{array}$ & $\begin{array}{l}\text { ClinicalTrials.gov Identifier: } \\
\text { NCT03236935 }\end{array}$ \\
\hline FOLR1 & Vintafolide & $\begin{array}{l}\text { Non small cell lung } \\
\text { cancer(Under } \\
\text { Clinical Trials) }\end{array}$ & $\begin{array}{l}\text { ClinicalTrials.gov Identifier: } \\
\text { NCTO0511485 }\end{array}$ \\
\hline
\end{tabular}

CYTOKINE STORM

\section{Figure 3}

Repurposing of drugs used to lung cancer in COVID19. (A) Correlation analyses indicate a negative correlation between BDKRB1-IL6-IFNG network and genes coexpressed with ACE2 in lung cancer. r values 
were generated by a linear-fit model using Graph Pad Prism.(B) Schematic representing the regulators of cytokine storm. Integration of ACE2 and BDKRB1 with positive and negative regulators affectS the inflammatory milieu in lung cancers (C) Repurposing of drugs used in the treatment of lung cancer for COVID19 infection. *, $\mathrm{P}<0.05 ; * \star, \mathrm{P}<0.01 ; * \star *, \mathrm{P}<0.001, \mathrm{r}$ - Spearman's rank correlation coefficient.

\section{Supplementary Files}

This is a list of supplementary files associated with this preprint. Click to download.

- SupplementaryDrugsApprovedforLungCancer.pdf 